\title{
Morphological and Molecular Diagnosis of Necator americanus and Ancylostoma ceylanicum Recovered from Villagers in Northern Cambodia
}

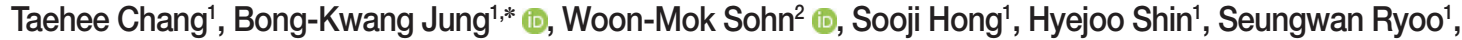 \\ Jeonggyu Lee ${ }^{1}$, Keon Hoon Lee ${ }^{1}$, Virak Khieu ${ }^{3}$, Rekol Huy ${ }^{3}$, Jong-Yil Chai ${ }^{1,4, *}$ (B) \\ 'Institute of Parasitic Diseases, Korea Association of Health Promotion, Seoul 07649, Korea; ${ }^{2}$ Department of Parasitology and Tropical Medicine, \\ and Institute of Health Sciences, Gyeongsang National University School of Medicine, Jinju 52727, Korea; ${ }^{3}$ National Center for Parasitology, \\ Entomology and Malaria Control, Ministry of Health, Phnom Penh, Cambodia; ${ }^{4}$ Department of Tropical Medicine and Parasitology, Seoul National \\ University College of Medicine, Seoul 03080, Korea
}

\begin{abstract}
Human hookworm infections caused by adult Ancylostoma spp. and Necator americanus are one of the most important tropical diseases. We performed a survey of intestinal helminths using the Kato-Katz fecal examination technique targeting 1,156 villagers residing in 2 northern provinces (Preah Vihear and Stung Treng) of Cambodia in 2018. The results revealed a high overall egg positive rate of intestinal helminths (61.9\%), and the egg positive rate of hookworms was $11.6 \%$. Nine of the hookworm egg positive cases in Preah Vihear Province were treated with $5-10 \mathrm{mg} / \mathrm{kg}$ pyrantel pamoate followed by purging with magnesium salts, and a total of 65 adult hookworms were expelled in diarrheic stools. The adult hookworms were analyzed morphologically and molecularly to confirm the species. The morphologies of the buccal cavity and dorsal rays on the costa were observed with a light microscope, and the nucleotide sequences of mitochondrial cytochrome $c$ oxidase subunit 1 (cox1) gene were analyzed. The majority of the hookworm adults $(90.7 \%)$ were N. americanus, whereas the remaining 9.3\% were Ancylostoma ceylanicum, a rare hookworm species infecting humans. The results revealed a high prevalence of hookworm infections among people in a northern part of Cambodia, suggesting the necessity of a sustained survey combined with control measures against hookworm infections.
\end{abstract}

Key words: Necator americanus, Ancylostoma ceylanicum, fecal examination, morphological diagnosis, molecular diagnosis, cox1, Cambodia

\section{INTRODUCTION}

Hookworms are nematode parasites infecting humans and animals through contact with the 3rd stage larvae via cutaneous route or ingestion of vegetables contaminated with the larvae [1]. In humans, hookworm infections are one of the most important neglected tropical diseases affecting 576-740 million people globally and causing physical and intellectual growth retardation and iron deficiency anemia [1,2]. Like other soil-transmitted helminthiases (STHs), hookworm infections are typically assessed by disability-adjusted life years (DALY) since they cause more disability than death [1]. Ac-

\footnotetext{
- Received 3 October 2020, revised 3 November 2020, accepted 3 November 2020.

*Corresponding authors (cjy@snu.ac.kr; mulddang@gmail.com)

() 2020, Korean Society for Parasitology and Tropical Medicine

This is an Open Access article distributed under the terms of the Creative Commons Attribution Non-Commercial License (https://creativecommons.org/licenses/by-nc/4.0) which permits unrestricted non-commercial use, distribution, and reproduction in any medium, provided the original work is properly cited.
}

cording to the DALY estimated by WHO, the disease burden from hookworm infections exceeds important tropical diseases such as African trypanosomiasis, Chagas disease, leprosy, dengue fever, and schistosomiasis [3]. In addition, hookworms more affect vulnerable and marginalized people than those who are not, and aggravate socio-economic inequality [4].

Based on the situation in 2010, Southeast Asia was reported to be the region with the 3rd highest hookworm prevalence followed by South Asia and sub-Saharan Africa; 77 million infected cases (12.6\%) were estimated to be present in Southeast Asia [5]. In Cambodia, 9.6-57.4\% of people residing in rural areas were reported to be infected with hookworms [6-8]. In particular, in Rovieng District, Preah Vihear Province, 124 (57.4\%) of 218 people examined were positive for hookworm eggs [6]. These eggs were moleculary confirmed to be Necator americanus (51.6\%; 64/124) and Ancylostoma ceylanicum (51.6\%; 64/124) equally, and a few cases (8 cases) were mixed infected with these 2 hookworm species and/or with Ancylosto- 
ma duodenale [6]. However, after this report, little is known about the prevalence, species composition, and infection dynamics of hookworms in Cambodia.

The objective of the present study was to determine and update the infection status of hookworms in humans living in northern parts of Cambodia. We obtained 65 adult hookworms expelled from infected people after chemotherapy and purging, and the worms were analyzed morphologically and molecularly to confirm the species of each hookworm.

\section{MATERIALS AND METHODS}

\section{Study design and participants}

Institute of Parasitic Diseases, Korea Association of Health Promotion (KAHP), Seoul, Korea, in cooperation with the National Center for Parasitology, Entomology and Malaria Control (CNM), Phnom Penh, Cambodia, surveyed intestinal parasitic infections in 2 northern provinces (5 villages each) of Cambodia, Preah Vihear and Stung Treng, in May 2018. Each participant was asked to submit a stool sample. Those with high intensity of hookworm infections in a village of Preah Vihear Province were recruited for a further procedure, including anthelmintic treatment and purging. The fecal examination was conducted by members of the Institute of Parasitic Diseases, KAHP, in cooperation with personnel of the Parasitology Section, CNM. The morphological and molecular studies were performed at the Institute of Parasitic Diseases, KAHP.

\section{Ethical issues}

The procedures of the present study were approved by the National Ethics Committee for Health Research, Ministry of Health, Cambodia (IRB no. NECHR 099, dated 27 April, 2018). Written informed consent was obtained from each participant. For children under 18 years of age, the informed consent was obtained from the children's parents, legal guardian, or appropriate literate substitute. All relevant authorities were informed of the study purpose and procedures.

\section{Fecal examinations, chemotherapy, and purging}

A total of 1,156 fecal samples collected from village people residing in 2 northern provinces were transported to CNM. The fecal specimens were examined by the Kato-Katz thick smear technique using light microscopes (Olympus CX23, Olympus Life-Science, Tokyo, Japan). The positive rate of helminth eggs and eggs per gram (EPG) of feces for each hel- minth were recorded. The Kampong Sangkae village (Chhaeb District) located in a northeastern area of Preah Vihear Province, bordered with Lao PDR, showed a high prevalence of hookworms and was selected as the target village for chemotherapy and adult hookworm recovery. Nine patients were recruited and treated with $5 \mathrm{mg} / \mathrm{kg}$ pyrantel pamoate followed by purging with magnesium salts. The worms discharged in diarrheic stools were collected, washed in water, and stored in 70-80\% ethanol until morphological and molecular analyses.

\section{Morphological study of adult hookworms}

The adult hookworm specimens were cleared in lactophenol for $30 \mathrm{~min}$ at room temperature and mounted on glass slides with glycerine jelly. The slides were then morphologically examined with an optical microscope (Leica D2500, Leica Microsystems, Wetzlar, Germany) to confirm the characteristic structures, including the buccal cavity of males and females, and bursa and dorsal rays on the costa in male worms.

\section{Molecular analysis on adult hookworms}

The parasite DNA was extracted from the middle part of the worms using the DNeasy Blood \& Tissue kit (QIAGEN, Hilden, Germany) following the manufacturer's instructions. DNA was eluted in a final volume of $50 \mu$ l. The protocol for conventional PCR followed the one described by Zhan et al. [9]. PCR amplification was performed in a $20 \mu \mathrm{l} 2 \mathrm{X}$ MasterMix (Mgmed, Seoul, Korea). Sequencing of the PCR product was performed in a gene analysis company (Macrogen Inc., Seoul, Korea) using the Sanger sequencing method. A phylogenetic tree of mitochondrial cytochrome $c$ oxidase subunit 1 (cox1) gene was constructed from the representative selection of sequences available in GenBank using the maximum-likelihood method employing Tamura-nei model of nucleotide substitution with 1,000 bootstrap replications.

\section{RESULTS}

Of the 1,156 fecal samples examined, 134 (11.6\%) were positive for hookworm eggs, including 43 (12.0\%) of 359 samples from Preah Vihear and 91 (11.4\%) of 797 samples from Stung Treng Province (Table 1). The Kampong Sangkae village, Preah Vihear Province showed 20 (22.5\%) egg positive villagers among 89 examined, and 9 of them were selected for adult worm recovery. A total of 65 adult hookworms, including $59 \mathrm{~N}$. americanus and 6 A. ceylanicum, were collected from 
the 9 enrolled patients after anthelmintic treatment and purging.

Morphological characteristics of adult hookworms, N. americanus and A. ceylanicum, are shown in Fig. 1A-D. N. americanus has a relatively narrow buccal cavity provided with a ventral and a dorsal pair of semilunar cutting plates $(v p, d p)$, which is a distinguishing feature of different hookworm species (Fig. 1A) [10]. It also has a subdorsal pair of tooth $(d t)$ in the depth of the buccal cavity (Fig. 1A). At the posterior end of N. americanus (adult male), the bursa has ventral, dorsal (dr), and lateral rays, and the end of the dorsal rays are typically divaricated (Fig. 1B). On the other hand, in A. ceylanicum, a pair of large

Table 1. The egg positive rate of hookworms among local people in 2 northern provinces of Cambodia

\begin{tabular}{llcc}
\hline Province & \multicolumn{1}{c}{ Village } & $\begin{array}{c}\text { No. of people } \\
\text { examined }\end{array}$ & $\begin{array}{c}\text { No. infected } \\
(\%)\end{array}$ \\
\hline Preah Vihear & Kampong Pou & 52 & $2(3.8)$ \\
& Kampong Chey & 42 & $10(23.8)$ \\
& Kampong Sangkae & & \\
& Kampong Sralau & 74 & $20(22.5)$ \\
& Kampong Sami & 50 & $3(10.8)$ \\
Stung Treng & Subtotal & 359 & $43(12.0)$ \\
& O' Chay & 125 & $20(16.0)$ \\
& Kanhchanh Tuek & 114 & $5(4.4)$ \\
& Ti Team & 93 & $18(19.4)$ \\
& Srae Russei & 204 & $25(12.3)$ \\
& Peam Khes & 261 & $23(8.8)$ \\
Total & Subtotal & 797 & $91(11.4)$ \\
\hline
\end{tabular}

This table has been modified from Chang et al. [25] who reported 2 cases of Taenia saginata infection in Preah Vihear Province, Cambodia. aThe village (Chhaeb district) where residents were recruited for treatment with pyrantel pamoate and purging for recovery of adult hookworms. tooth $(t)$ upside and another pair of smaller tooth below are symmetrically seen near the anterior end of the the buccal cavity (Fig. 1C), as described by Looss in 1911 [10]. The oral aperture (oa) is bigger and round-shaped (Fig. 1C) in comparison with Ancylostoma braziliense, which tends to be smaller and longer in the longitudinal plane. Near the posterior end of $A$. ceylanicum (adult male), the structure named as the copulatory bursa has the ventral, dorsal $(d r)$, and lateral rays. Among these, the end of the dorsal rays are characteristically trifurcated (Fig. 1D).

Direct sequencing of adult hookworms supported the morphological diagnosis of each hookworm and revealed the species combination of hookworms among the infected people. The representative sequences obtained in this study were deposited in GenBank under accession nos. MT074036-MT074043. Out of 65 adult hookworms, 90.7\% (59/65) appeared to be $N$. americanus and 9.3\% (6/65) were A. ceylanicum. The other species of human-infecting hookworms, including A. duodenale, were not detected. Eight of our 9 patients harbored only $\mathrm{N}$. americanus (1-24 worms), and 1 was infected only with A. ceylanicum (2 worms) (Table 2). Three patients were infected with both $N$. americanus (1-14 worms) and A. ceylanicum (1-2 worms) (Table 2).

The phylogenetic tree distinctly separated the hookworm specimens into 5 clusters of 2 species, $N$. americanus (groups A-C) and A. ceylanicum (group D-E) (Fig. 2). The N. americanus isolates in this study $(\mathrm{n}=59)$ were strongly associated with $N$. americanus isolates from Brazil (group A) and China (groups B-C). The group A consisted of 49 worms (GenBank accession no. MT074038), group B 1 worm (no. MT074037), and group C 9 worms (no. MT074036).
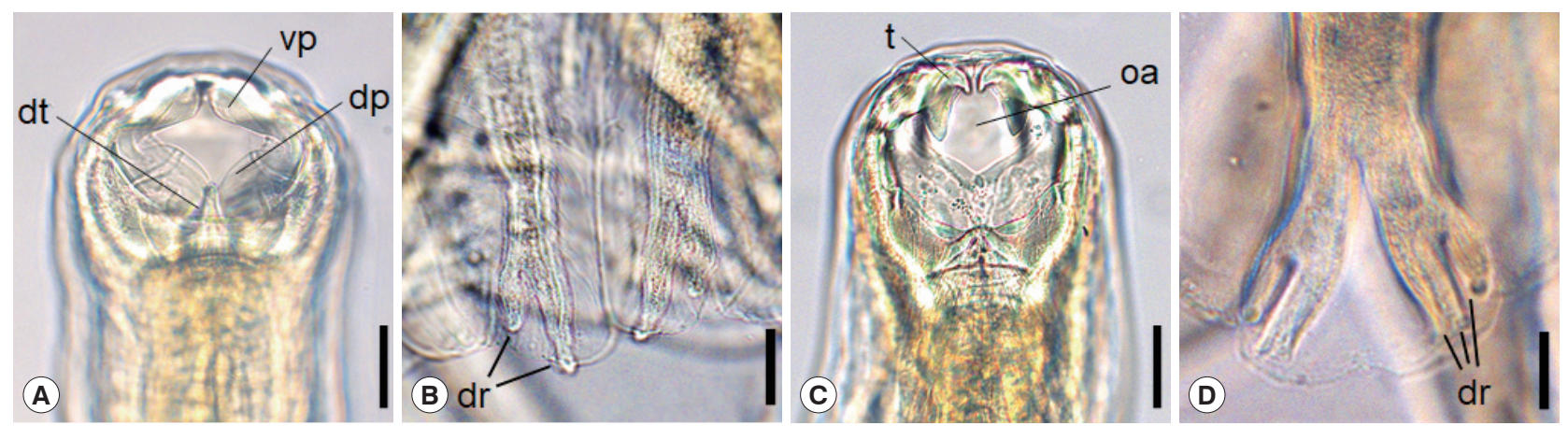

Fig. 1. Morphological characteristics of Necator americanus (A, C), and Ancylostoma ceylanicum (B, D). The anterior end of $N$. americanus $(A)$ and $A$. ceylanicum $(C)$ showing the buccal capsule with cutting plate or teeth. Scale bar $=0.03$ mm. Enlarged views of dorsal rays on the copulatory bursa of $N$. americanus (B) and $A$. ceylanicum (D). Scale bar $=0.05 \mathrm{~mm}$. Tooth (t), oral aperture (oa), dorsal tooth (dt), ventral cutting plate (vp), dorsal cutting plate (dp), dorsay ray (dr). 
Regarding A. ceylanicum, the isolate group D (no. MT074042) obtained from 2 patients $(n=5)$ were closely associated with the isolate from Solomon Islands (AP017674) but distinct from Ancylostoma caninum (EU007444), Ancylostoma tubaeforme (KY070315), and A. duodenale (AP017676) isolates. Another isolate group E (no. MT074043) from 1 patient $(\mathrm{n}=1)$ was morphologically diagnosed as A. ceylanicum but molecularly a little distant (97.3\% identity) from the isolate group D (no.

Table 2. Collection of hookworms among 9 people in Kampong Sangkae village, Preah Vihear Province, Cambodia

\begin{tabular}{lccc}
\hline & & \multicolumn{2}{c}{ No. of hookworms collected } \\
\cline { 3 - 4 } Case no. & Age \&sex & $\begin{array}{c}\text { Necator } \\
\text { americanus }\end{array}$ & $\begin{array}{c}\text { Ancylostoma } \\
\text { ceylanicum }\end{array}$ \\
\hline 1 & $27 \mathrm{~F}$ & 9 & 0 \\
2 & $40 \mathrm{M}$ & 1 & 0 \\
3 & $27 \mathrm{M}$ & 2 & 0 \\
4 & $26 \mathrm{M}$ & 14 & 1 \\
5 & $23 \mathrm{~F}$ & 1 & 0 \\
6 & $38 \mathrm{~F}$ & 24 & 0 \\
7 & $24 \mathrm{M}$ & 7 & 2 \\
8 & $36 \mathrm{~F}$ & 1 & 1 \\
9 & $21 \mathrm{M}$ & 0 & 6 \\
\hline Total & - & 59 & 2 \\
\hline
\end{tabular}

MT074042) and the A. ceylanicum isolate from Solomon Islands (AP017674). However, it was more distant from A. caninum (EU007444; 89.5\%), A. tubaeforme (KY070315; 89.9\%), and A. duodenale (AP017676; 89.4\%). Thus, we regarded this as an A. ceylanicum isolate.

\section{DISCUSSION}

The present study revealed a high prevalence of hookworm infections among people in Preah Vihear and Stung Treng Province of Cambodia bordered with Lao PDR. The species of hookworms were confirmed to be $N$. americanus in their majority and A. ceylanicum (a zoonotic hookworm of dogs and cats) in a little proportion through morphological and molecular analyses of adult worms expelled from each patient. To our best knowledge, this study is the first which analyzed the species of hookworms morphologically and molecularly using adult specimens recovered from humans.

$N$. americanus was found to be the dominant hookworm species in our study, followed by A. ceylanicum, similar to other molecular studies conducted in Southeast Asian countries [1114]. Traub et al. [11] reported that 5 out of 7 humans in Bang-

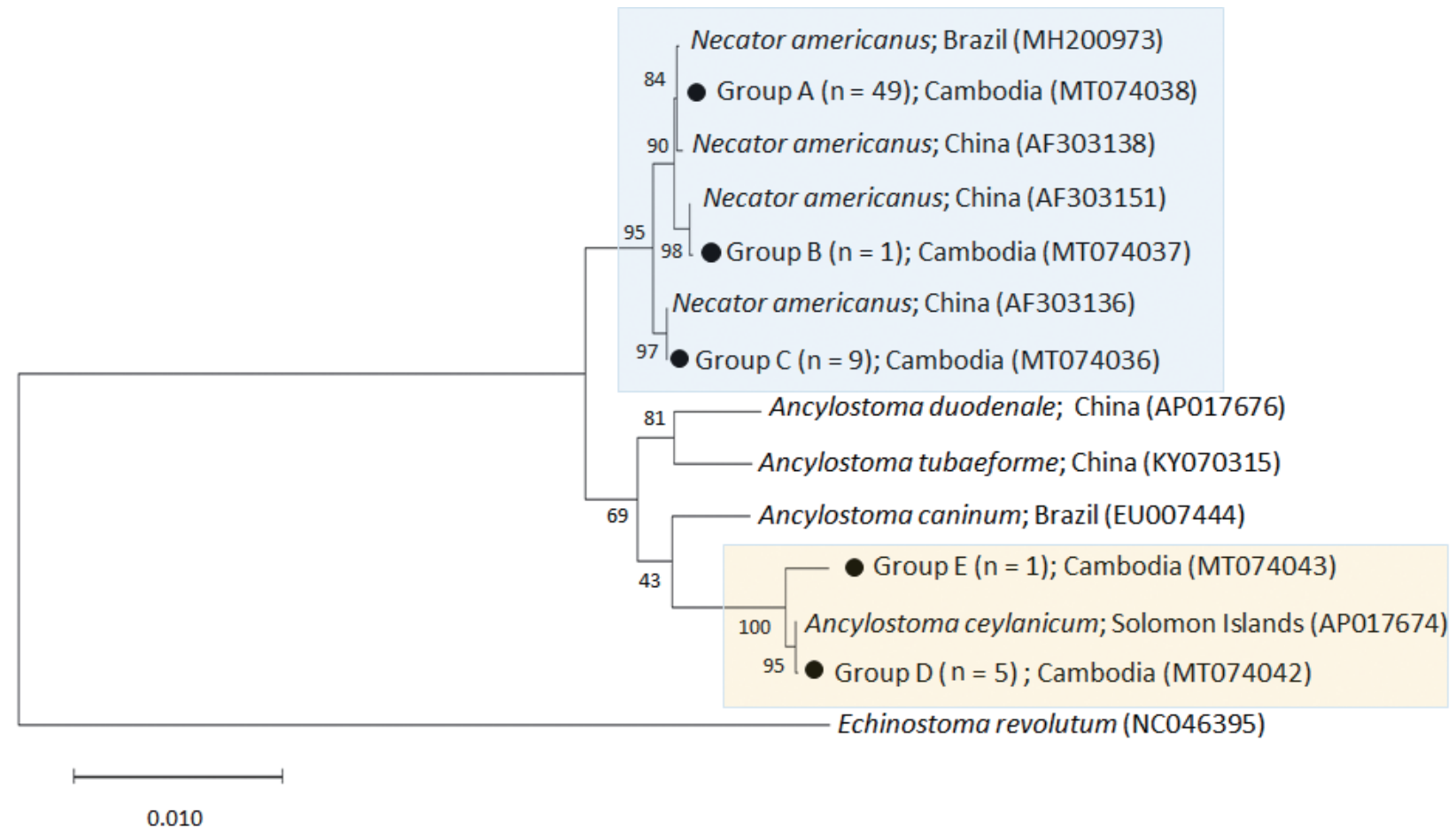

Fig. 2. A phylogenetic tree of hookworm species drawn with cox1 DNA sequences using the maximum-likelihood method employing Tamura-nei model of nucleotide substitution with 1,000 bootstrap replications. Black dots (•) indicate the sequences identified in this study. Echinostoma revolutum was used as an outgroup. 
kok, Thailand were infected with N. americanus and 2 were with A. ceylanicum analyzed by sequencing of internal transcribed spacer (ITS) region (ITS1-5.8S rDNA-ITS2) using eggs in feces. Similar results were reported in Chachoengsao Province, east of Bangkok [12], northern provinces of Lao PDR [13], and West Malaysia [14].

Our results were contrasting to the findings of a previous study by Inpankaew et al. [6] conducted in a different district of the same province in Cambodia, i.e., Rovieng District. In their study, the eggs of hookworms in human feces were moleculary analyzed, and infections with $N$. americanus and A. ceylanicum were confirmed equally in high numbers, 64 (51. 6\%) of 124 cases for each species [6]. In our study, the hookworms were predominantly $N$. americanus, and only a few (6 worms) were A. ceylanicum. Inpankaew et al. [6] hypothesized that preventive chemotherapy targeting humans in the absence of concurrent hygiene and animal health programs on dogs and cats may be a factor leading to the emergence of A. ceylanicum infection in humans in Rovieng District. Based on our study, another possible hypothesis was that the population of dogs and cats infected with A. ceylanicum might be higher in Rovieng District than in Chhaeb District (present study), although this needs verification.

Human A. ceylanicum infection was considered accidental and looked upon as a negligible item; but it is currently acknowledged as an important reemerging parasitic zoonosis distributed almost all geographical areas affecting a substantial number of human population [15]. One of the issues includes the susceptibility of humans to A. ceylanicum infection. When Lane [16] first discovered A. ceylanicum infection in humans (14 of 150 prisoners) in India, each individual harboured only $1-2$ worms comprising less than $0.1 \%$ of total hookworm burden which was comprised mainly of $N$. americanus and A. duodenale. Chowdhury and Schad [17] also recovered 1-2 A. ceylanicum together with 3-55 A. duodenale and 19-161 N. americanus adult worms from 16 volunteers in India treated with bephenium hydroxynaphthoate in combination with tetrachlorethylene or thiabendazole. In our study, the burden of A. ceylanicum was also low, only 1-2 worms per infected person. However, it is referable that Velasquez and Cabrera [18] found a Filippino woman infected with $23 \mathrm{~A}$. ceylanicum adult males $(\mathrm{n}=11)$ and females $(\mathrm{n}=12)$ after treatment with atabrine. The eggs of A. ceylanicum were present in human feces in sufficient quantities to be detected by conventional PCR targeting the rDNA gene $[6,14]$. Based on these reports, we could infer that
A. ceylanicum can fully grow and sexually mature in the human intestine.

The prevalence of hookworm infection (11.6\%) in the present study (Chhaeb District, Preah Vihear Province) was lower than that (46.7\%) of the study conducted in 2010 in 6 districts of Preah Vihear Province excluding Chhaeb District [19] and that (26.6\%) of another study conducted in 2012 in a different area (Rovieng District) of the same province [6]. This result may be attributed to an efficient handling of STHs nationwide in Cambodia, showing more than $80 \%$ coverage of mass drug administration (MDA) (twice a year with mebendazole) following WHO guidelines [20]. However, it is still unsatisfactory because higher than $10 \%$ prevalence of hookworms does not represent successful control in these areas. According to the WHO and UNICEF joint monitoring programme conducted in 2012, Cambodia had the lowest rates of access to improved WASH (water, sanitation and hygiene) program where open defecation is still widely practiced [20]. A significant risk factor for hookworm infection is contacting infective larvae of human or animal hookworms in soil via barefoot or skin. Therefore, improvement in community hygiene as well as animal health seem to be essential for STH control in Cambodia $[2,6]$.

Recent findings have shown that the efficacy of albendazole and mebendazole against hookworms has been decreasing over time [21]. The cure rate of hookworms using mebendazole was only $32.5 \%$ which might be due to an anthelmintic drug resistance [21]. For preventive chemotherapy against hookworm infections in endemic areas, co-administration of drugs with different efficacy profiles, mebendazole, albendazole, pyrantel pamoate, and/or oxantel pamoate, is recommended [22].

Further studies are needed to confirm the prevalence of hookworms with molecular methods. PCR-based methods were proved to be a superior alternative to conventional microscopy-based techniques for detecting hookworm eggs in fecal samples [23,24]. This was also proven in the research [6] which revealed a significantly higher rate of infection with the molecular-based examination (57.4\%) than the microscopybased examination (26.6\%). Besides, behaviors of residents and environmental surveys on endemic areas are necessary to analyze the potential risk factors of hookworm infections.

Conclusively, our study confirmed that hookworm infections are endemic in 2 northern provinces of Cambodia, Preah Vihear and Stung Treng. A national scale deworming programme using proper anthelmintic drugs such as albendazole 
combined with pyrantel pamoate is needed with improved water supplies and sanitation for substantial reductions in hookworm prevalence.

\section{ACKNOWLEDGMENTS}

We are grateful to the participants and local health authorities in Preah Vihear and Stung Treng provinces. We appreciate the staff of the National Center for Parasitology, Entomology and Malaria Control, Ministry of Health, Phnom Penh, Cambodia, for their help in this survey.

\section{CONFLICT OF INTEREST}

The authors declare no conflicts of interest.

\section{REFERENCES}

1. Bethony J, Brooker S, Albonico M, Geiger SM, Loukas A, Diemert D, Hotez PJ. Soil-transmitted helminth infections: ascariasis, trichuriasis, and hookworm. Lancet 2006; 367: 1521-1532. https://doi.org/10.1016/S0140-6736(06)68653-4

2. Hotez PJ, Brooker S, Bethony JM, Bottazzi M, Loukas A, Xiao S. Hookworm infection. N Eng J Med 2004; 351: 799-807. https:// doi.org/10.1056/NEJMra032492

3. Hotez PJ, Zhan B, Bethony JM, Loukas A, Williamson A, Goud G, Hawdon JM, Dobardzic A, Dobardzic R, Ghosh K, Bottazzi M, Mendez S, Zook B, Wang Y, Liu S, Essiet-Gibson I, Chung-Debose S, Xiao S, Knox D, Meagher M, Inan M, Correa-Oliveira R, Vilk P, Shepherd HR, Brandt W, Russell PK. Progress in the development of a recombinant vaccine for human hookworm disease: the Human Hookworm Vaccine Initiative. Int J Parasitol 2003; 33: 12451258. https://doi.org/10.1016/s0020-7519(03)00158-9

4. de Silva NR, Brooker S, Hotez PJ, Montresor A, Engels D, Savioli L. Soil-transmitted helminth infections: updating the global picture. Trends Parasitol 2003; 19: 547-551. https://doi.org/10.1016/ j.pt.2003.10.002

5. Loukas A, Hotez PJ, Diemert D, Yazdanbakhsh M, McCarthy JS, Correa-Oliveira R, Croese J, Bethony JM. Hookworm infection. Nat Rev Dis Primers 2016; 2: 16088. https://doi.org/10.1038/ nrdp. 2016.88

6. Inpankaew T, Schär F, Dalsgaard A, Khieu V, Chimnoi W, Chhoun C, Sok D, Marti H, Muth S, Odermatt P, Traub RJ. High prevalence of Ancylostoma ceylanicum hookworm infections in humans, Cambodia, 2012. Emerg Infect Dis 2014; 20: 976-982. https://doi.org/10.3201/eid2006.131770

7. Yong TS, Chai JY, Sohn WM, Eom KS, Jeoung HG, Hoang EH, Yoon CH, Jung BK, Lee SH, Sinuon M, Socheat D. Prevalence of intestinal helminths among inhabitants of Cambodia (20062011). Korean J Parasitol 2014; 52: 661-666. https://doi.org/10. 3347/kjp.2014.52.6.661

8. Forrer A, Khieu V, Schär F, Vounatsou P, Chammartin F, Marti H, Muth S, Odermatt P. Strongyloides stercoralis and hookworm coinfection: spatial distribution and determinants in Preah Vihear Province, Cambodia. Parasit Vectors 2018; 11: 33. https://doi. org/10.1186/s13071-017-2604-8

9. Zhan B, Li T, Xiao S, Zheng F, Hawdon JM. Species-specific identification of human hookworms by PCR of the mitochondrial cytochrome oxidase I gene. J Parasitol 2001; 87: 1227-1229. https://doi.org/10.1645/0022-3395(2001)087[1227:SSIOHH]2. 0.CO;2

10. Beaver PC, Jung RC, Cupp EW. Clinical Parasitology. 9th ed. Philadelphia, USA. Lea \& Febiger. 1984.

11. Traub RJ, Inpankaew T, Sutthikornchai C, Sukthana Y, Thompson RC. PCR-based coprodiagnostic tools reveal dogs as reservoirs of zoonotic ancylostomiasis caused by Ancylostoma ceylanicum in temple communities in Bangkok. Vet Parasitol 2008; 155: 67-73. https://doi.org/10.1016/j.vetpar.2008.05.001

12. Jiraanankul V, Aphijirawat W, Mungthin M, Khositnithikul R, Rangsin R, Traub RJ, Piyaraj P, Naaglor T, Taamasri P, Leelayoova $\mathrm{S}$. Incidence and risk factors of hookworm infection in a rural community of central Thailand. Am J Trop Med Hyg 2011; 84: 594-598. https://doi.org/10.4269/ajtmh.2011.10-0189

13. Conlan JV, Khamlome B, Vongxay K, Elliot A, Pallant L, Sripa B, Blacksell SD, Fenwick S, Thompson RCA. Soil-transmitted helminthiasis in Laos: a community-wide cross-sectional study of humans and dogs in a mass drug administration environment. Am J Trop Med Hyg 2012; 86: 624-634. https://doi.org/10.4269/ ajtmh.2012.11-0413

14. Ngui R, Lim YAL, Traub R, Mahmud R, Mistam M. Epidemiological and genetic data supporting the transmission of Ancylostoma ceylanicum among human and domestic animals. PLoS Negl Trop Dis 2012; 6: e1522. 10.1371/journal.pntd.0001522

15. Traub RJ. Ancylostoma caninum, a re-emerging but neglected parasitic zoonosis. Int J Parasitol 2013; 43: 1009-1015. https://doi. org/10.1016/j.ijpara.2013.07.006

16. Lane C. Ancylostoma ceylanicum, a new human parasite. Indian Med Gaz 1913; 48: 217-218.

17. Chowdhury AB, Schad GA. Ancylostoma ceylanicum: a parasite of man in Calcutta and environs. Am J Trop Med Hyg 1972; 21: 300-301. https://doi.org/10.4269/ajtmh.1972.21.300

18. Velasquez CC, Cabrera BC. Ancylostoma ceylanicum (Looss, 1911) in a Filipino woman. J Parasitol 1968; 54: 430-431.

19. Khieu V, Schär F, Forrer A, Hattendorf J, Marti H, Duong S, Vounatsou P, Muth S, Odermatt P. High prevalence and spatial distribution of Strongyloides stercoralis in rural Cambodia. PLoS Negl Trop Dis 2014; 8: e2854. https://doi.org/10.1371/journal.pntd.0002854

20. Pose RR. Neglected tropical diseases: the case of Cambodia. Development Progress Case Study Report 2014; 1-60.

21. Moser W, Schindler C, Keiser J. Efficacy of recommended drugs against soil transmitted helminths: systematic review and network meta-analysis. BMJ 2017; 357: j4307. https://doi.org/10.1136/ bmj.j4307 
22. Moser W, Sayasone S, Xayavong S, Bounheuanng B, Puchkov M, Huwyler J, Hattendorf J, Keiser J. Efficacy and tolerability of triple drug therapy with albendazole, pyrantel pamoate, and oxantel pamoate compared with albendazole plus oxantel pamoate, pyrantel pamoate plus oxantel pamoate, and mebendazole plus pyrantel pamoate and oxantel pamoate against hookworm infections in school-aged children in Laos: a randomised, singleblind trial. Lancet Infect Dis 2018; 18: 729-737. https://doi.org/ 10.1016/S1473-3099(18)30220-2

23. Traub RJ, Robertson ID, Irwin P, Mencke N, Thompson RCA. Application of a species-specific PCR-RFLP to identify Ancylostoma eggs directly from canine faeces. Vet Parasitol 2004; 123:
245-255. https://doi.org/10.1016/j.vetpar.2004.05.026

24. Sato M, Sanguankiat S, Yoonuan T, Pongvongsa T, Keomoungkhoun M, Phimmayoi I, Boupa B, Moji K, Waikagul J. Copromolecular identification of infections with hookworm eggs in rural Lao PDR. Trans R Soc Trop Med Hyg 2010; 104: 617-622. https://doi.org/10.1016/j.trstmh.2010.06.006

25. Chang T, Jung BK, Sohn WM, Hong S, Shin H, Ryoo S, Lee J, Lee KH, Khieu V, Huy Rekol, Chai JY. Molecular diagnosis of Taenia saginata tapeworms from two residents of Northern Cambodia. Korean J Parasitol 2020; 58: 201-204. https://doi.org/10.3347/ kjp.2020.58.2.201 
